June 1995

\title{
Treatment of Chronic Mental Illness
}

Anu A. Matorin, MD

Baylor College of Medicine, Houston Texas

Follow this and additional works at: https://jdc.jefferson.edu/jeffjpsychiatry

Part of the Psychiatry Commons

Let us know how access to this document benefits you

\section{Recommended Citation}

Matorin, MD, Anu A. (1995) "Treatment of Chronic Mental Illness," Jefferson Journal of Psychiatry. Vol. 12 : Iss. 2 , Article 12.

DOI: https://doi.org/10.29046/JJP.012.2.009

Available at: https://jdc.jefferson.edu/jeffjpsychiatry/vol12/iss2/12

This Article is brought to you for free and open access by the Jefferson Digital Commons. The Jefferson Digital Commons is a service of Thomas Jefferson University's Center for Teaching and Learning (CTL). The Commons is a showcase for Jefferson books and journals, peer-reviewed scholarly publications, unique historical collections from the University archives, and teaching tools. The Jefferson Digital Commons allows researchers and interested readers anywhere in the world to learn about and keep up to date with Jefferson scholarship. This article has been accepted for inclusion in Jefferson Journal of Psychiatry by an authorized administrator of the Jefferson Digital Commons. For more information, please contact: JeffersonDigitalCommons@jefferson.edu. 


\title{
Treatment of Chronic Mental Illness
}

\author{
RESIDENT'S GUIDE TO TREATMENT OF PEOPLE \\ WITH CHRONIC MENTAL ILLNESS \\ (GAP Report 136; 1993) \\ Formulated by the Committee on Psychiatry and the Community, \\ Group for the Advancement of Psychiatry. \\ American Psychiatric Press, Inc., 1993, 230 pages, $\$ 30.00$
}

Anu A. Matorin, M.D.

Treatment of chronic mental illness is often inadequately addressed in residency training programs. The Committee on Psychiatry and the Community, a group with long-standing involvement in the treatment of the chronically mentally ill, state that the purpose of this book is to "help residents gain a basic understanding of the clinical principles and techniques involved in the treatment of this population." Preliminary work on this guide began in 1987 after completion of a previous report, "A Family Affair: Helping Families Cope With Mental Illness-A Guide for the Professions," (GAP Report 119, 1986). "A Family Affair" grew out of a review of letters written to "Dear Abby" by readers who had a family member with chronic mental illness. The letters detailed the frustration experienced by families attempting to find a doctor who could effectively work with the patient, the family, and the "system." The authors correctly point out that the lack of adequate clinical training in the treatment of this population, especially for the beginning clinician, may contribute to an experience that is both discouraging and frustrating for the patient and the clinician. To gain a better understanding of residents' concerns as well, the authors surveyed a group of psychiatric residents and wrote this book in an attempt to answer clinical questions raised by residents. The guide more than lives up to its goal of presenting practical, clinically useful information, focusing on interpersonal interventions with emphasis on the benefits and rewards to be gained by both patients as well as their treating physicians.

The guide is very readable, clearly written, and conveys a sense of optimism regarding treatment of this population. The authors send an extremely important, often overlooked message that, in their view, "successful outcome is defined by acceptance, relative peace of mind, and progress to the next step." They deftly guide the reader through the inevitable "ups and downs" in the treatment of patients with chronic mental illness, pointing out how a clinician armed with sensitivity, patience, and hope can bring about a meaningful and rewarding treatment experience.

Anu A. Matorin, M.D. recently completed her residency training in the Department of Psychiatry at Baylor College of Medicine in Houston, Texas. 
The book is divided into eleven chapters with appendices detailing specific assessment tools as well as a selected reading list at the end. More importantly, the use of well thought out case vignettes woven throughout the text provide cohesiveness and allow for a very practical way to integrate important clinical information. There are also tables summarizing important concepts throughout the book that can be used as a quick glance or easy reference.

Chapter 1, entitled "Baptism of Fire," introduces us to three patients and their doctors in typical clinical settings. These three complex scenarios set the stage as the authors reveal an overall framework for assessment and treatment by tying in the disease model, the psychosocial component, as well as a long term program for rehabilitation and recovery. These scenarios are then "revisited" in following chapters. The next section focuses on engagement and assessment of patients (Chapter 2) and families (Chapter 3). The authors point out that "safety, empathy, and communication are the key elements in developing rapport and engaging the patient." The cases then highlight these important issues. The section offering detailed strategies and techniques for the prevention of violence was especially useful and practical. In Chapter 3 case vignettes entitled, "The family in denial," "The angry, resistant family," "The needy, highly involved family," and "The burned-out family," reveal how to cope with these common types of encounters in a step-by-step fashion and how to engage these families in the treatment process.

Treatment issues comprise the next section of the book. Highlights from this section include Chapter 6 which is entitled, "The Art of Prescribing Medication." It specifically explores resistance as it applies to compliance, as well as offering strategies for improving medication compliance. I felt this chapter was particularly thorough as it openly addresses denial, medication effects, autonomy issues, education, and the use of coercive strategies for patients "unwilling or unable to maintain medication compliance." Individual psychotherapy with chronically mentally ill patients is addressed in the following chapter. With the use of case vignettes, various issues such as length and frequency of sessions, content of sessions, transference, and termination are addressed. Although this chapter begins with a disclaimer that "not all chronically mentally ill patients benefit from individual psychotherapy," by the end the authors had gently and successfully persuaded me that therapy in this population can indeed proceed with sensitivity and style. The remaining two chapters in this section offer specific strategies to involve the family in treatment as well as outlining strategies for "mobilizing" community programs in the treatment of chronic patients.

The final section discusses treatment of special populations all too frequently encountered by residents in various treatment settings. Chapter 10 discusses treatment of patients with dual diagnosis, specifically chronic mental illness and substance use disorders, while the last chapter concludes with treatment strategies for the homeless mentally ill population. Specific assessment tools, including protocols for biopsychosocial, hospital, community, and legal systems, as well as alcohol and drug intake protocols are included in Appendices A-F. Although following the continuing 
case examples can be complex and confusing at times, there is an index of the continuing case examples at the end for easy reference.

This guide is a must for psychiatric residents at all levels of training, however beginning residents may find it particularly useful. Additionally, it easily lends itself to be included in resident seminars and to supplement individual supervision. It focuses specifically on questions and concerns voiced by residents and therefore, for residents-in-training, this comprehensive guide is invaluable. Most importantly, using continuing clinical cases, the authors skillfully point out how, with flexibility, treatment of the chronically mentally ill can be satisfying and rewarding. 